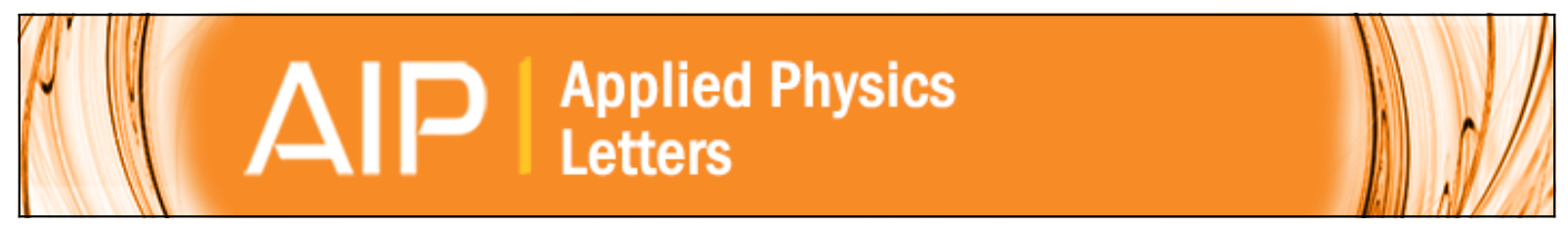

\title{
A Finemet-type alloy as a low-cost candidate for high-temperature magnetic refrigeration
}

V. Franco, J. S. Blázquez, C. F. Conde, and A. Conde

Citation: Applied Physics Letters 88, 042505 (2006); doi: 10.1063/1.2167803

View online: http://dx.doi.org/10.1063/1.2167803

View Table of Contents: http://scitation.aip.org/content/aip/journal/apl/88/4?ver=pdfcov

Published by the AIP Publishing

\section{Articles you may be interested in}

Optimization of the giant magnetoimpedance effect of Finemet-type microwires through the nanocrystallization J. Appl. Phys. 115, 17A313 (2014); 10.1063/1.4863484

Effect of $\mathrm{P}$ addition on nanocrystallization and high temperature magnetic properties of low $\mathrm{B}$ and $\mathrm{Nb}$ containing FeCo nanocomposites

J. Appl. Phys. 111, $07 A 301$ (2012); 10.1063/1.3670056

The magnetocaloric effect in soft magnetic amorphous alloys

J. Appl. Phys. 101, 09 C503 (2007); 10.1063/1.2709409

Publisher's Note: "Low-temperature magnetic properties and the crystallization behavior of FINEMET alloy" [J. Appl. Phys. 93, $6182(2003)]$

J. Appl. Phys. 94, 2771 (2003); 10.1063/1.1589613

Low-temperature magnetic properties and the crystallization behavior of FINEMET alloy

J. Appl. Phys. 93, 6182 (2003); 10.1063/1.1565829

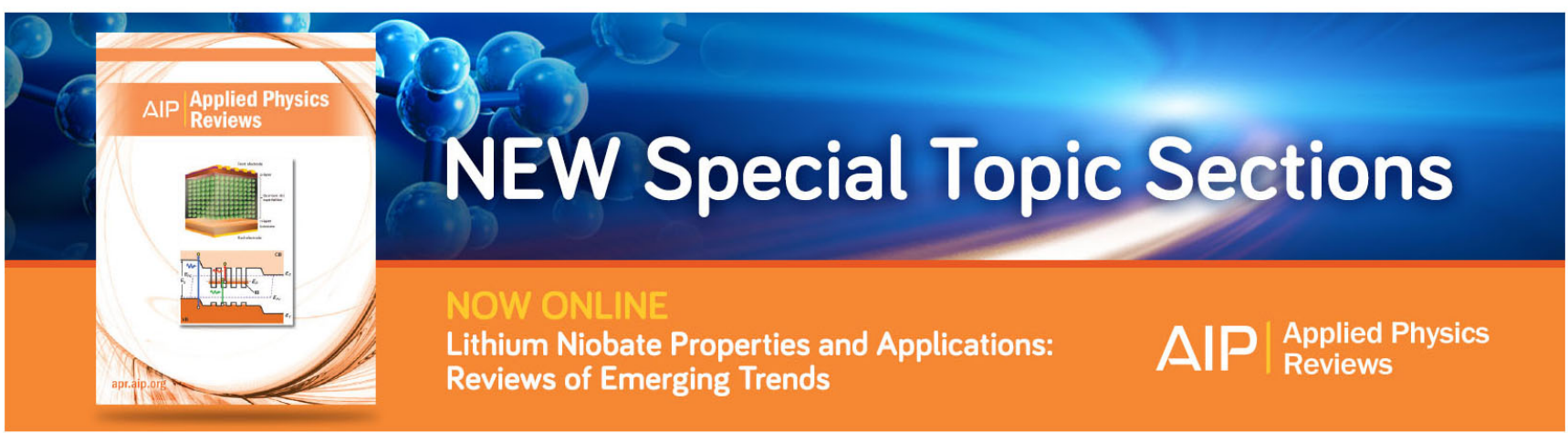




\title{
A Finemet-type alloy as a low-cost candidate for high-temperature magnetic refrigeration
}

\author{
V. Franco, J. S. Blázquez, C. F. Conde, and A. Conde ${ }^{a)}$ \\ Dpto. Física de la Materia Condensada, ICMSE-CSIC, Universidad de Sevilla, P.O. Box 1065, \\ 41080 Sevilla, Spain
}

(Received 6 October 2005; accepted 12 December 2005; published online 24 January 2006)

\begin{abstract}
The refrigerant capacity $(R C)$ of $\mathrm{Fe}_{68.5} \mathrm{Mo}_{5} \mathrm{Si}_{13.5} \mathrm{~B}_{9} \mathrm{Cu}_{1} \mathrm{Nb}_{3}$ alloy is studied. For the amorphous sample, $R C=63 \mathrm{~J} \mathrm{~kg}^{-1}$ for an optimal reversible cycle with cold and hot ends at $328 \mathrm{~K}$ and $520 \mathrm{~K}$, respectively, for a maximum applied field $H=15 \mathrm{kOe}$. Nanocrystallization diminishes both the peak entropy change and $R C$ of the material. Although the measured $R C$ is smaller than for $\mathrm{Gd}_{5} \mathrm{Ge}_{1.9} \mathrm{Si}_{2} \mathrm{Fe}_{0.1}\left(240 \mathrm{~J} \mathrm{~kg}^{-1}\right.$ for $\left.H=50 \mathrm{kOe}\right)$, the Mo-Finemet alloy is more than 20 times cheaper, the applied field employed is smaller, and the temperature span of the optimal cycle is increased. This makes this alloy a promising material for high-temperature refrigeration. (C) 2006 American Institute of Physics. [DOI: 10.1063/1.2167803]
\end{abstract}

The search for materials suitable to be used as magnetic refrigerants (exploiting the magnetocaloric effect) close to or above room temperature is a field of current interest. ${ }^{1,2}$ In order to exhibit a big magnetocaloric response, a material needs to have a big magnetic moment and a strong temperature dependence of magnetization close to the working temperature. This second condition is related to a magnetic phase transition. The change in magnetization is more abrupt for first-order phase transitions, but the associated magnetic hysteresis that appears in some materials may reduce the actual efficiency of the cooling process. ${ }^{3}$ Second-order phase transitions produce a broader peak in the magnetic entropy change, with a smaller magnitude. However, the refrigerant capacity $(R C)$ of a material in a reversible cycle is connected to the entropy absorbed by the refrigerant at the cold end of the cycle and its temperature $\operatorname{span}^{4}$ and, therefore, the peak entropy change is not the most relevant parameter in characterizing the material. Research on high-temperature magnetic refrigeration has been mainly centered around rare-earth containing materials, 5,6 although there have been some studies on transition metal-based materials due to their lower costs. $^{7-10}$ In this work, we study the $R C$ of a Mo-containing Finemet-type alloy and its evolution along nanocrystallization, with the motivation of searching for a virtually nonhysteretic low-cost material with magnetocaloric response at moderate fields and working temperature above room temperature.

Amorphous ribbon, $\sim 25 \mu \mathrm{m}$ thick and $\sim 10 \mathrm{~mm}$ wide, with nominal composition $\mathrm{Fe}_{68.5} \mathrm{Mo}_{5} \mathrm{Si}_{13.5} \mathrm{~B}_{9} \mathrm{Cu}_{1} \mathrm{Nb}_{3}$ was prepared by planar flow casting. The amorphous character of the as-quenched alloy was checked by x-ray diffraction and transmission electron microscopy (TEM) observations. Calorimetric [differential scanning calorimetry (DSC)] scans were obtained in a Perkin-Elmer DSC-7 at a heating rate of $10 \mathrm{~K} / \mathrm{min}$. TEM observations were performed in a Philips CM200 $(200 \mathrm{kV})$. The field dependence of magnetization was measured in a Lakeshore 7407 vibrating sample magnetometer using a maximum applied field of $H=15 \mathrm{kOe}$ with field steps of $50 \mathrm{Oe}$, for constant temperatures in the range of $325-625 \mathrm{~K}$ with increments of $10 \mathrm{~K}$. The magnetic entropy

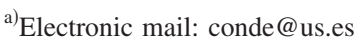

change due to the application of a magnetic field $H$ has been calculated from the numerical derivative of the $M(H, T)$ curves with respect to temperature and subsequent integration in field. Preheating of the samples was done in a halogen-lamp furnace under vacuum by increasing the temperature at $10 \mathrm{~K} / \mathrm{min}$ up to the target temperature, $T_{\text {heat }}$, (in the range of $648-883 \mathrm{~K}$ ) and subsequent free cooling. The crystallization fraction for the different samples was obtained from the integration of the DSC signal from the onset temperature up to $T_{\text {heat }}$ normalized to the total area of the nanocrystallization peak, while mean grain size was obtained from TEM images.

The devitrification transformation of this alloy takes place in two main stages, as usually found in this type of alloy. ${ }^{11-13}$ Each of them is detected as a well-resolved exothermal peak in the DSC records. The first one, with a peak temperature of $872 \mathrm{~K}$, corresponds to the precipitation of $\alpha$-Fe, Si nanocrystals into the amorphous matrix. The second crystallization stage, with a peak temperature of $974 \mathrm{~K}$, is related to the full crystallization of the sample. Mo addition enhances the thermal stability of both the amorphous and nanocrystalline microstructure. ${ }^{11,14}$

TEM images of different preheated samples are shown in Fig. 1. The sample heated up to $648 \mathrm{~K}$ shows the absence of contrast typical of amorphous materials, indicating that only stress relaxation has occurred in the sample. ${ }^{14}$ For $T_{\text {heat }}=843 \mathrm{~K}$, corresponding to $\sim 10 \%$ of the nanocrystallization process, the mean grain size is $\sim 6 \mathrm{~nm}$. Preheating up to higher temperatures produces an increase in both the crystalline volume fraction and mean grain size $(\sim 10 \mathrm{~nm}$ for

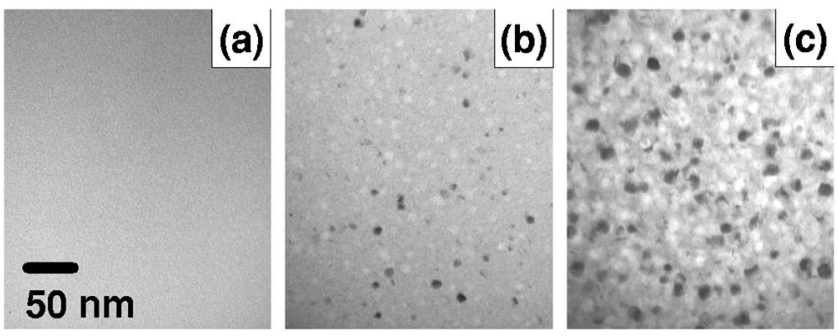

FIG. 1. TEM images of samples preheated up to (a) $648 \mathrm{~K}$, (b) $843 \mathrm{~K}$, and (c) $883 \mathrm{~K}$. 


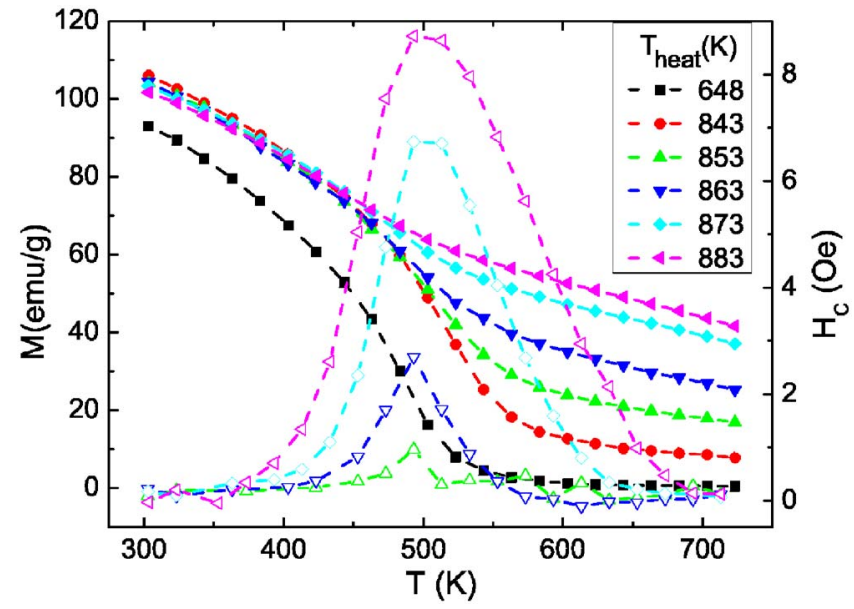

FIG. 2. (Color online) Temperature dependence of the magnetization at $5 \mathrm{kOe}$ (solid symbols) and coercivity (open symbols) of preheated samples. Coercivity data for the first two samples are below the field sensitivity of the system.

$T_{\text {heat }}=883 \mathrm{~K}$; i.e., $\sim 70 \%$ of the nanocrystallization process).

The temperature dependence of the magnetization (at $5 \mathrm{kOe}$ ) of the studied samples is presented in Fig. 2. The nanocrystalline samples have a two-phase magnetic character. The Curie temperature of the amorphous phase, $T_{c}^{\mathrm{am}}$, increases at the beginning of nanocrystallization, although it progressively decreases as nanocrystallization proceeds. The temperature dependence of coercivity (Fig. 2) can be explained on the basis of the random anisotropy model extended to two-phase systems. ${ }^{15}$ For $T<T_{c}^{\mathrm{am}}$, the ferromagnetic character of the matrix facilitates the exchange coupling of the nanocrystals, resulting in the averaging out of the magnetic anisotropy. As $T_{c}^{\mathrm{am}}$ is approached, the matrix can no longer transmit the exchange, as indicated by the progressive increase in coercivity. The reduction in coercivity at higher temperatures is associated with the transition to superparamagnetism of the $\alpha$ - Fe, $\mathrm{Si}$ nanoparticles. It has been shown that this transition is controlled by the dipolar interaction between the particles, both in Finemet ${ }^{16}$ and Nanoperm-type ${ }^{17}$ nanocrystalline materials. The maximum value of coercivity is related to the effective dipolar interaction field. As nanocrystallization proceeds, the increase in grain size and the reduction of the average distance between the nanocrystals enhance the dipolar coupling between the particles, as shown by the progressive increase in the maximum value of coercivity, $H_{c}^{\max }$. It is worth mentioning that these samples present a reduction in $H_{c}^{\max }(\sim 9 \mathrm{Oe})$ with respect to the Cr-containing Finemet ( $\sim 50$ Oe) (Ref. 16) and Cr-Mo containing Nanoperm-type alloys $(\sim 150 \mathrm{Oe}),{ }^{17}$ both at early stages of nanocrystallization. The reduced value of hysteresis losses is a beneficial feature for magnetic refrigerant materials. ${ }^{6}$

Figure 3 shows the temperature dependence of the magnetic entropy change corresponding to an applied field $H$ $=15 \mathrm{kOe}$ for the different studied samples. The presented behavior is similar to that calculated for interacting superparamagnetic particles. ${ }^{18}$ The peak entropy change $\left(\Delta S_{M}^{\mathrm{pk}}\right)$ continuously decreases as nanocrystallization proceeds [Fig. 4(b)]. The corresponding temperature shows a similar evolution to that of $T_{c}^{\mathrm{am}}$, obtained from the "kink point" of the low-field $M(T)$ curves, with an increase at the beginning of

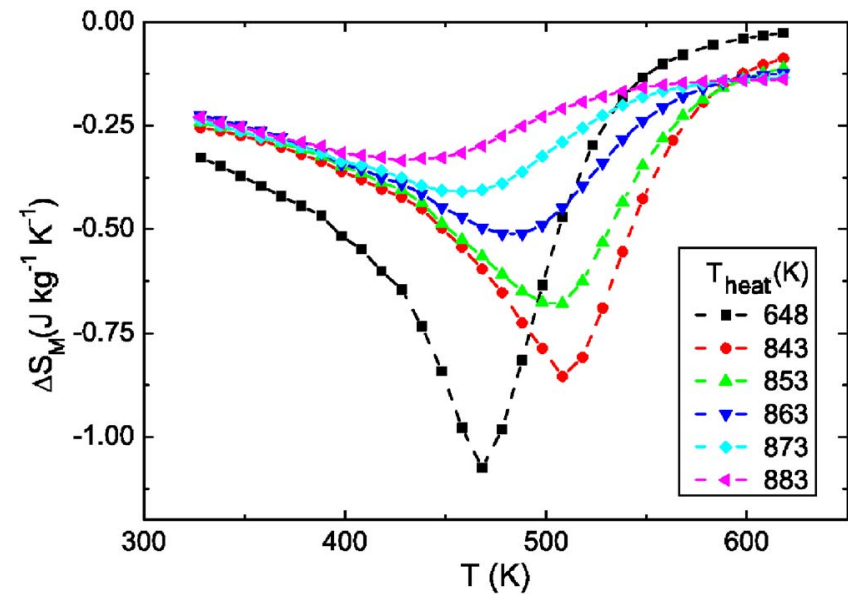

FIG. 3. (Color online) Temperature dependence of the magnetic entropy change for preheated samples. Lines are a guide for the eyes.

nanocrystallization and a subsequent slight reduction as the transformation progresses.

$R C$ is measured in literature by different methods: (a) The product of the peak entropy change times the full width at half maximum of the peak, (b) by numerically integrating the area under the $\Delta S_{M}(T)$ curves, using the temperatures at half-maximum of the peak as the integration limits, and (c) defining the $R C$ of a reversible refrigeration cycle operating between $T_{h}$ and $T_{c}$ (the temperatures of the hot and cold reservoirs, respectively) as $R C=\Delta S_{M} \Delta T,{ }^{4}$ where $\Delta S_{M}$ is the magnetic entropy change at the hot and cold ends of the cycle and $\Delta T=T_{h}-T_{c}$. The optimal refrigeration cycle is that which maximizes the $R C$. Figure 4(c) shows that the $R C$ of

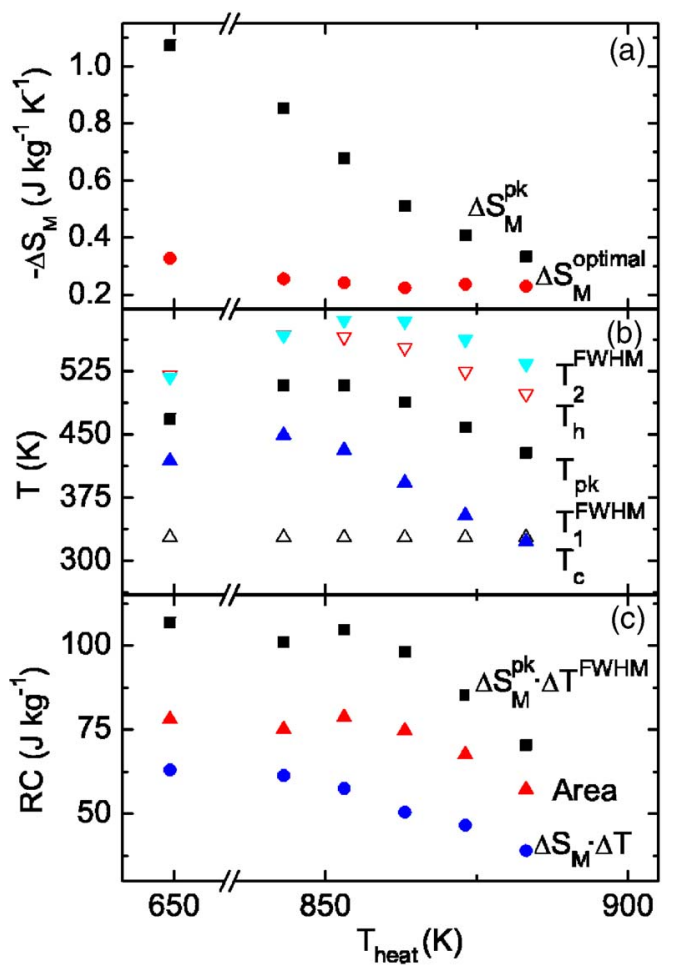

FIG. 4. (Color online) Preheating dependence of: (a) The maximum magnetic entropy change (squares) and the entropy change for the optimal reversible cycle (circles); (b) peak entropy change temperature (squares), temperatures at half maximum (solid triangles) and of the optimal cold and hot reservoirs (open triangles); and (c) refrigerant capacity $(R C)$ calculated by three different methods. 
the nanocrystalline material is not improved as compared to that of the relaxed amorphous sample.

For the amorphous sample and $H=15 \mathrm{kOe}$, the peak value of the entropy change is $1.1 \mathrm{~J} \mathrm{~kg}^{-1} \mathrm{~K}^{-1}$, the same order of magnitude of $\mathrm{Gd}_{5} \mathrm{Ge}_{1.9} \mathrm{Si}_{2} \mathrm{Fe}_{0.1}\left(7 \mathrm{~J} \mathrm{~kg}^{-1} \mathrm{~K}^{-1}\right.$ for $H$ $=50 \mathrm{kOe}){ }^{6}$ another material for high-temperature refrigeration with reduced hysteresis losses. When comparing the $R C$ for the optimal reversible cycle of these two materials, the present alloy has $R C=63 \mathrm{~J} \mathrm{~kg}^{-1}$ for $T_{c}=328 \mathrm{~K}, T_{h}=520 \mathrm{~K}$, and $H=15 \mathrm{kOe}$, while $\mathrm{Gd}_{5} \mathrm{Ge}_{1.9} \mathrm{Si}_{2} \mathrm{Fe}_{0.1}$ has $R C=240 \mathrm{~J} \mathrm{~kg}^{-1}$ for $T_{c} \approx 250 \mathrm{~K}, T_{h} \approx 340 \mathrm{~K}$, and $H=50 \mathrm{kOe}$. Despite the reduction in $R C$ for the Finemet alloy, it has to be considered that the applied field is significantly smaller (no superconducting magnet is required), the operating temperature range is strongly displaced to higher temperatures and, moreover, the material is more than 20 times cheaper than the Gd-based one. The field dependence of the $R C$ of the amorphous Finemet sample displays a linear behavior in the studied field range (regression coefficient $r=0.9996)$. A simple linear extrapolation to $50 \mathrm{kOe}$ gives an estimate of $R C \sim 220 \mathrm{~J} \mathrm{~kg}^{-1}$, comparable to that of the Gd-based alloy. In order to finetune the $T_{c}$ and temperature span for Finemet-type alloys, studies of composition optimization are in progress.

This work was supported by the Spanish Government and EU-FEDER (Project MAT 2004-04618) and the PAI of Junta de Andalucía. One of the authors (J.S.B.) is grateful to Junta de Andalucía for a research contract.
${ }^{1}$ A. M. Tishin, in Handbook of Magnetic Materials Vol. 12, edited by K. H. J. Buschow (Elsevier, Amsterdam, 1999), pp. 395-524.

${ }^{2}$ K. A. Gschneidner, Jr. and V. K. Pecharsky, Annu. Rev. Mater. Sci. 30, 387 (2000).

${ }^{3}$ E. M. Levin, V. K. Pecharsky, and K. A. Gschneidner, Jr., Phys. Rev. B 62, R14625 (2000).

${ }^{4}$ M. E. Wood and W. H. Potter, Cryogenics 25, 667 (1985).

${ }^{5}$ V. K. Pecharsky and K. A. Gschneidner, Jr., Phys. Rev. Lett. 78, 4494 (1997).

${ }^{6}$ V. Provenzano, A. J. Shapiro, and R. D. Shull, Nature (London) 429, 853 (2004).

${ }^{7}$ O. Tegus, E. Bruck, K. H. J. Buschow, and F. R. de Boer, Nature (London) 415, 150 (2002)

${ }^{8}$ D. Wang, K. Peng, B. Gu, Z. Han, S. Tang, W. Qin, and Y. Du, J. Alloys Compd. 358, 312 (2003).

${ }^{9}$ I. Skorvanek and J. Kovac, Czech. J. Phys. 54, D189 (2004).

${ }^{10}$ S. Atalay, H. Gencer, and V. S. Kolat, J. Non-Cryst. Solids 351, 2373 (2005).

${ }^{11}$ C. F. Conde, V. Franco, and A. Conde, Philos. Mag. B 76, 489 (1997).

${ }^{12}$ J. S. Blázquez, C. F. Conde, and A. Conde, Appl. Phys. Lett. 79, 2898 (2001).

${ }^{13}$ J. S. Blázquez, J. M. Borrego, C. F. Conde, A. Conde, and J. M. Greneche, J. Phys.: Condens. Matter 15, 3957 (2003).

${ }^{14}$ V. Franco, C. F. Conde, and A. Conde, J. Non-Cryst. Solids 287, 366 (2001).

${ }^{15}$ A. Hernando, M. Vázquez, T. Kulik, and C. Prados, Phys. Rev. B 51, 3581 (1995).

${ }^{16}$ V. Franco, L. F. Kiss, T. Kemény, I. Vincze, C. F. Conde, and A. Conde, Phys. Rev. B 66, 224418 (2002).

${ }^{17}$ V. Franco, C. F. Conde, A. Conde, and L. F. Kiss, Phys. Rev. B 72, 174424 (2005).

${ }^{18}$ L. H. Bennet, R. D. McMichael, L. J. Swartzendruber, R. D. Shull, and R. E. Watson, J. Magn. Magn. Mater. 104, 1094 (1992). 